\title{
Freiheit, die ich meine
}

Liebe Kolleginnen, liebe Kollegen,

es ist das vornehmste Recht unserer Exekutive, Normierungen in Form von Gesetzen und Verordnungen zu erlassen. Dieses Normierungsrecht soll einen für alle gültigen Ordnungsrahmen schaffen, der das Miteinander der Menschen oder der sie vertretenden Interessengruppen in für jeden nachvollziehbare Richtlinien fasst. Soweit die Theorie.

Wie sieht die Ausübung dieses Rechtes in Wirklichkeit aus? Der Einzelne in der repräsentativen Demokratie hat nur eine Chance, seine Interessen zu vertreten, indem er zur Wahl geht oder - in besonderen Fällen - den Petitionsausschuss des Bundestages anruft. Wer den Normierungsprozess in seinem Sinne beeinflussen will, muss entweder an einer Schlüsselstelle der Gesellschaft sitzen, wie Fluglotsen oder Lokführer, oder er versucht, die Abgeordneten von der Richtigkeit seiner Vorstellungen zu überzeugen. Gemeinhin wird das als „Lobbyarbeit“ bezeichnet.

\section{Ablenken von Handlungsohnmacht}

Eine beliebte Masche der Politik besteht darin, tatsächliche oder vermeintliche Probleme zu erkennen und gezielt aufzubauschen, um anschließend populistische Forderungen zu stellen und durchzusetzen, die von der eigenen Handlungsohnmacht ablenken sollen.

Jüngstes Beispiel: Die Idee des Bundesinnenministers, die ärztliche Schweigepflicht im Zusammenhang mit Terrorismusbekämpfung zur Disposition zu stellen. Auch in diesem sensiblen Bereich, wie zuvor schon beim Thema Korruption, gab und gibt es ausreichende Möglichkeiten für Zahnärzte und Ärzte, bei Gefahr für Leib und Leben Anderer, staatliche Stellen zu informieren. Andere in ihrem Vertrauensverhältnis geschützte Berufe, wie Geistliche oder Abgeordnete, werden in diesem Zusammenhang nicht ins Visier genommen.

Wer wohlmeinend ist, kann hinter diesen Dingen mangelnde Sensitivität für das spezielle Arzt-Patienten-Verhältnis vermuten. Man kann aber auch unterstellen, dass die Kettengesetzgebung wechselnder Regierungen ein anderes Ziel verfolgt: Nämlich die Strukturen im Gesundheitssystem so umzugestalten, dass der staatliche Durchgriff in Form einer hypertrophen Ministerialbürokratie immer und überall Priorität hat.

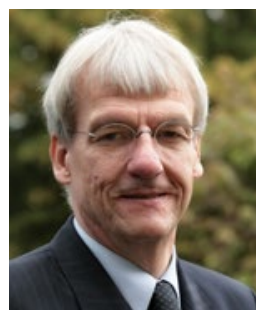

Harald Schrader

Bundesvorsitzender des FVDZ

\section{Gesetze zur reinen Machtausübung}

In diesem Kontext bekommt die rechtfertigende Indikation für Gesetze ein anderes Gewicht. „Wenn es nicht notwendig ist, ein Gesetz zu machen, dann ist es notwendig, kein Gesetz zu machen", war die tiefe - und bis heute vollkommen nachvollziehbare - Überzeugung des französischen Philosophen und Staatstheortikers Montesquieu. Heute scheint das Gegenteil zum Normalfall - oder sollte man „Normierfall“ sagen? - zu werden. Man gewinnt den Eindruck, dass manche Gesetze nicht mehr ordnend normierende Funktion haben (sollen), sondern der reinen Machtausübung auf Zeit Gewählter dienen. Dieses kurzfristige Denken in Machterhaltungskategorien zerstört gewachsene Strukturen wie das Vertrauensverhältnis zwischen Arzt und Patient.

In diesem Sinne ist die Erinnerung an Max von Schenkendorfs Gedicht:

Freiheit, die ich meine, Die mein Herz erfüllt

keine romantisierende Reminiszenz an napoleonische Freiheitskriege, sondern eine Aufforderung an uns alle, das Recht zur freien Berufsausübung, wie es unseren Patienten am besten dient, immer und auf allen Ebenen zu verteidigen.

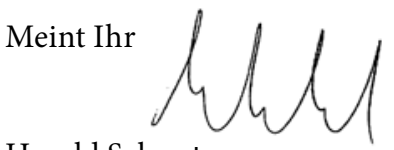

Harald Schrader 